OPEN ACCESS

Edited by:

J. David Spafford

University of Waterloo, Canada

Reviewed by:

Christine Beeton,

Baylor College of Medicine

United States

Robert Brenner

The University of Texas Health

Science Center at San Antonio,

United States

*Correspondence:

Richard Barrett-Jolley

RBJ@Liverpool.ac.uk

Specialty section This article was submitted to Membrane Physiology and Membrane Biophysics, a section of the journal Frontiers in Physiology

Received: 03 September 2019 Accepted: 27 February 2020 Published: 24 March 2020

Citation:

Haidar O, O'Neill N, Staunton CA, Bavan S, O'Brien F, Zouggari S, Sharif U, Mobasheri A, Kumagai K and Barrett-Jolley R (2020) Pro-inflammatory Cytokines Drive Deregulation of Potassium Channel

Expression in Primary Synovia

Fibroblasts. Front. Physiol. 11:226. doi: 10.3389/fphys.2020.00226

\section{Pro-inflammatory Cytokines Drive Deregulation of Potassium Channel Expression in Primary Synovial Fibroblasts}

\author{
Omar Haidar', Nathanael O'Neill', Caroline A. Staunton', Selvan Bavan', Fiona O'Brien', \\ Sarah Zouggari', Umar Sharif', Ali Mobasheri ${ }^{2,3,4,5}$, Kosuke Kumagai ${ }^{1,6}$ and \\ Richard Barrett-Jolley ${ }^{1,5 *}$
}

${ }^{1}$ Institute of Ageing and Chronic Disease, University of Liverpool, Liverpool, United Kingdom, ${ }^{2}$ Research Unit of Medical Imaging, Physics and Technology, University of Oulu, Oulu, Finland, ${ }^{3}$ Department of Regenerative Medicine, State Research Institute Centre for Innovative Medicine, Vilnius, Lithuania, ${ }^{4}$ Department of Orthopedics and Department of Rheumatology \& Clinical Immunology, UMC Utrecht, Utrecht, Netherlands, ${ }^{5}$ Versus Arthritis Centre for Sport, Exercise and Osteoarthritis Research, Queen's Medical Centre, Nottingham, United Kingdom, ${ }^{6}$ Department of Orthopaedic Surgery, Shiga University of Medical Science, Shiga, Japan

The synovium secretes synovial fluid, but is also richly innervated with nociceptors and acts as a gateway between avascular joint tissues and the circulatory system. Resident fibroblast-like synoviocytes' (FLS) calcium-activated potassium channels $\left(K_{\mathrm{Ca}}\right)$ change in activity in arthritis models and this correlates with FLS activation.

Objective: To investigate this activation in an in vitro model of inflammatory arthritis; $72 \mathrm{~h}$ treatment with cytokines TNF $\alpha$ and IL $1 \beta$.

Methods: FLS cells were isolated from rat synovial membranes. We analyzed global changes in FLS mRNA by RNA-sequencing, then focused on FLS ion channel genes and the corresponding FLS electrophysiological phenotype and finally modeling data with ingenuity pathway analysis (IPA) and MATLAB.

Results: IPA showed significant activation of inflammatory, osteoarthritic and calcium signaling canonical pathways by cytokines, and we identified $\sim 200$ channel gene transcripts. The large $K_{\mathrm{Ca}}(\mathrm{BK})$ channel consists of the pore forming Kcnma1 together with $\beta$-subunits. Following cytokine treatment, a significant increase in Kcnma1 RNA abundance was detected by qPCR and changes in several ion channels were detected by RNA-sequencing, including a loss of BK channel $\beta$-subunit expression Kcnmb1/2 and an increase in Kcnmb3. In electrophysiological experiments, there was a decrease in over-all current density at $20 \mathrm{mV}$ without change in chord conductance at this potential.

Conclusion: TNF $\alpha$ and IL1 $\beta$ treatment of FLS in vitro recapitulated several common features of inflammatory arthritis at the transcriptomic level, including increase in Kcnma1 and Kcnmb3 gene expression.

Keywords: TNF $\alpha$, IL1 $\beta$, inflammation, synovial fibroblast, ion channel 


\section{INTRODUCTION}

Rheumatoid arthritis (RA) and osteoarthritis (OA) are degenerative diseases that target articular joint structures resulting in pain, loss of function and frequent disability. Whilst RA is an established inflammatory condition, the contribution of inflammatory processes to $\mathrm{OA}$ was less well known until recently. Mediators of inflammation (i.e., including pro-inflammatory cytokines) contribute to the development of synovitis, which is known to drive disease progression in RA. In contrast, it is thought that in OA, synovitis can be caused by the release of cartilage fragments and meniscal damage that in turn, activate synovial lining cells (Fernandez-Madrid et al., 1995; Roemer et al., 2013; Mathiessen and Conaghan, 2017). How inflammation drives joint destruction is not fully known. One feature of synovitis, however, is the presence of major pro-inflammatory cytokines, such as interleukin-1 $\beta$ (IL-1 $\beta$ ), tumor necrosis factor alpha $(\mathrm{TNF} \alpha)$, and interleukin 6 (IL-6), resulting in suppression of collagen and proteoglycan synthesis, increased inflammatory signaling, and protease expression and activation (Martel-Pelletier et al., 1999).

Management of arthritis has significantly improved in recent years', however, remission is rarely achieved, and many patients remain unresponsive to conventional and/or biologic treatments. In addition, current therapies and treatments are associated with notable side effects that can pose great challenges for long-term treatment, especially in patients with cardiovascular co-morbidities. For example, some drugs can increase the risk of cardiovascular disease or significantly impair immune responses, rendering patients more susceptible to infections and cancer (Kahlenberg and Fox, 2011). Therefore, new therapeutic options and novel targets are needed that lead to pronounced improvement without inducing unwanted side effects and thus avoiding the need for joint replacement.

The synovium is the major barrier between the joint and the systemic circulation and plays a role in maintaining the health of articular cartilage (Sutton et al., 2009; Berenbaum, 2013). The synovium lubricates the articular surfaces and provides nutrients for chondrocytes within the avascular cartilage; it has been suggested that catabolic enzymes such as matrix metalloproteinase (MMPs) are produced by synovial cells and diffuse into the cartilage. The intimal lining layer of the synovium produces lubricious synovial fluid and is composed of two cell types in relatively equal proportions: Type A or macrophage-like synovial cells and Type B or fibroblasts like synoviocytes (FLS). FLS cells contribute to the structural integrity of the joints by controlling the composition of the synovial fluid and extracellular matrix (ECM) of the joint. The synovial environment changes physically, chemically, and physiologically with injury or the onset of disease and is thought to be a mediator in arthritis pain (Grubb, 2004; Sellam and Berenbaum, 2010; Kumahashi et al., 2011). FLS cells have been implicated in arthritis as they exhibit a transformed phenotype with increased invasiveness and production of various pro-inflammatory mediators that perpetrate inflammation and proteases that contribute to cartilage destruction (Noss and Brenner, 2008; Bartok and Firestein, 2010). Understanding the biology and regulation of FLS cells provides insight into the pathogenesis of inflammatory arthritis. FLS cells could potentially be targeted pharmacologically to produce increased volumes of synovial fluid as an alternative to intra-articular hyaluronan or synthetic fluid injection therapies. They are also a plausible analgesic target because they may interact with sensory neurons and have been described as "amplifiers" of neuropeptide mediated inflammation and pain.

To deepen our understanding of the synovium in the context of synovial joint health and disease, the electrophysiological profile of FLS cells needs to be characterized, along with the ion channels that are present. Ion channels are an essential component of any cell membrane that controls ion movement in and out of the cell and play an important role in a multitude of cell regulating processes, typically by modulating the membrane potential. Electrophysiological techniques have been used to characterize the biophysical properties of a number of different FLS preparations, including mouse, rabbit, bovine and human (Large et al., 2010; Friebel et al., 2014; Clark et al., 2017). The best available whole-cell mathematical model of the FLS is heavily dominated by a $\mathrm{Ca}^{2+}$-activated potassium conductance, with small added components of inward rectifiers, background and leak. A recent study by Kondo et al. (2018) demonstrated that human FLS express high levels of $\mathrm{Ca}^{2+}$. activated potassium channels and these ion channels were also identified in both RA-derived and rodent model FLS studies. Typically, $\mathrm{Ca}^{2+}$-activated channels couple with $\mathrm{Ca}^{2+}$ entry channels such as transient receptor potential (TRP) channels; they are both activated by the $\mathrm{Ca}^{2+}$ ions that enter and maintain the membrane potential hyperpolarized to "draw in" further $\mathrm{Ca}^{2+}$. In FLS, $\mathrm{Ca}^{2+}$-activated potassium channels appear to drive invasiveness of synoviocytes and progression of arthritis in both human and rodent RA models (Petho et al., 2016; Tanner et al., 2019), by increasing production of both inflammatory mediators and catabolic enzymes (Hu et al., 2012; Friebel et al., 2014; Tanner et al., 2015). This is a paradoxical effect for a potassium conductance, that would be predicted to hyperpolarize cells and reduce migration, proliferation and activity in general.

The synovium is an obvious target for the development of novel interventions in both RA and OA. The role of synovitis, the low-grade inflammation of the synovial lining of the joint, in OA progression is gradually emerging. Therefore, in this work we investigate the pathophysiology of cytokine induced synovitis in cultured synovial cells.

We investigate whether the TNF $\alpha$ and IL1 $\beta$ cytokine in vitro model of inflammation leads to a significant change of the BK ion channel and quantify the mechanism of this change. We use a combination of next generation RNA sequencing (NGS), qPCR, and patch-clamp electrophysiology to uncover several changes in potassium channel gene expression together with changes in cellular phenotype which involves a phenotypic switch in response to inflammation. 


\section{MATERIALS AND METHODS}

Further methodological details are included in the Supplementary Methods section (see Supplementary File S2).

\section{Animals}

Synovial cells were prepared from tissue from rats euthanized by Home Office Approved methods for unassociated reasons in line with the ARRIVE Guidelines. All rats were untreated/wild-type male adult Wistar.

\section{Preparation of FLS Cells}

Synovial fibroblasts were isolated from rat knee joints as described previously. Briefly, patella and menisci with attached synovial membranes were isolated and placed in 12-well plates in low glucose DMEM (Thermo Fischer, United Kingdom) with $20 \%$ fetal bovine serum (FBS), $100 \mathrm{U} / \mathrm{ml}$ penicillin, $100 \mu \mathrm{g} / \mathrm{ml}$ streptomycin and $2.5 \mu \mathrm{g} / \mathrm{ml}$ amphotericin B (Thermo Fischer, United Kingdom) at $37^{\circ} \mathrm{C}$ in a $5 \% \mathrm{CO}_{2}$ incubator. For the first 7 days medium was replaced daily whilst out-growing FLS emerged from the tissues. At 7 days residual tissue was discarded and cells cultured as normal; when confluent, cells were detached from the flask surface by $1 \%$ Trypsin-EDTA solution. The suspension was centrifuged $(340 \times g, 5 \mathrm{~min})$ and the resulting pellet was resuspended in culture medium (as above).

\section{Immunohistochemistry}

In brief, cell suspension at a density of $2.5 \times 10^{4} \mathrm{cell} / \mathrm{ml}$ was transferred to multiwall plates and fixed with $2 \%$ paraformaldehyde in PBS at room temperature. CD248 (an FLS marker) immunohistochemistry was performed using rabbit anti-CD248 primary antibody (Ab, 1:100 dilution; Abcam, Cambridge) and FITC-conjugated donkey Antirabbit IgG secondary antibody (Ab, 1:500 dilution; Jackson ImmunoResearch Laboratories). Non-specific binding was blocked as previously described (Mobasheri et al., 2005). After $24 \mathrm{~h}$ at $4^{\circ} \mathrm{C}$, cells were washed three times for 5 min with $0.05 \%$ SSC-20 and $0.005 \%$ Triton-X100. Slides were finally dipped into distilled water, air dried, and mounted with mounting media (Vectashield with DAPI). Cells were visualized with confocal microscopy.

\section{Real-Time PCR}

RNA extraction was carried out using the RNeasy Plus Micro kit, together with gDNA eliminator and MinElute spin columns (Qiagen, United Kingdom). cDNA synthesis (mRNA) was performed using the RT2 First Strand kit (Qiagen, Netherlands) according to the manufacturer's protocol. qPCR analysis was performed using the Stratagene MX3000P RT-PCR System (Stratagene, La Jolla, CA, United States) in a $25-\mu \mathrm{L}$ reaction mixture. Expression relative to housekeeper Rplp1 was calculated as $\Delta \mathrm{Ct}$.

\section{RNA "Next Generation Sequencing" (NGS)}

Figure 1 summarizes our NGS workflow. In brief, cells were treated with $10 \mathrm{ng} / \mathrm{ml}$ of both TNF- $\alpha+\operatorname{IL} 1 \beta$ (TNF- $\alpha$ from
Thermo Fischer, United Kingdom and IL1 $\beta$ from R\&D systems) for $72 \mathrm{~h}$. RNA extraction was carried out using the RNeasy Plus Micro kit (Qiagen, United Kingdom) according to the manufacturers protocol. Any RNA samples with concentrations of less than $5 \mu \mathrm{g} / \mathrm{ml}$ and/or purity (260/280 and 260/230) less than 1.8 were excluded. RNA samples were sent to GATCBiotech, Germany for sequencing. Samples were read as pairedend with a sequencing depth of $30 \mathrm{M}$ and a read length of 50 bp. Further details are included in Supplementary Methods (see Supplementary File S2). Further bioinformatics were performed with $\mathrm{R}$, for example the DAPCA package or our local installation of the Galaxy server suite (Afgan et al., 2018). Specific packages are mentioned in the text, Supplementary Methods (see Supplementary File S2) and Figure 1. Full data are available on the EBI array express database with accession number: E-MTAB-7798.

\section{Electrophysiology}

Electrophysiology was performed as described previously (Lewis et al., 2013) but using isolated FLS. Intracellular solution was $115 \mathrm{mM}$ gluconic acid/potassium salt, $26 \mathrm{mM} \mathrm{KCl,} 1 \mathrm{mM}$ $\mathrm{MgCl}_{2}$ (BDH, VWR International Ltd.), $5 \mathrm{mM}$ Ethylene glycol tetraacetic acid (EGTA), $10 \mathrm{mM}$ HEPES, pH 7.2. Extracellular (bath) solution was $140 \mathrm{mM} \mathrm{NaCl}, 5 \mathrm{mM} \mathrm{KCl}, 2 \mathrm{mM} \mathrm{CaCl}_{2}$ (Fluka Analytical cat\#: 21114), $1 \mathrm{mM} \mathrm{MgCl} 2,10 \mathrm{mM}$ HEPES, and $5 \mathrm{mM}$ Glucose, osmolality approximately $300 \mathrm{mOsm}, \mathrm{pH}$ 7.4. Junction potential $-14.4 \mathrm{mV}$ (Lewis et al., 2013). Thickwalled patch-pipettes were pulled from borosilicate glass capillary tubes (outer diameter $1.5 \mathrm{~mm}$, inner diameter $0.86 \mathrm{~mm}$; Intracel, United Kingdom) and gave a resistance of $\sim 8 \mathrm{M} \Omega$ when filled. Whole cell patch-clamp electrophysiology was performed on FLS cells using a Cairn Optopatch amplifier (Cairn Research, United Kingdom). To compare voltage-gated currents, we performed whole-cell patch clamp experiments with voltage steps starting from a holding potential of $-80 \mathrm{mV}$ for $2 \mathrm{~s}$. Recordings were filtered at $1 \mathrm{kHz}$, digitized at $3 \mathrm{kHz}$ and recorded on a computer using WinWCP 5.3.4 software (John Dempster, Strathclyde University, United Kingdom). All experiments were performed at room temperature $\left(18-22^{\circ} \mathrm{C}\right)$, and the results are expressed as the mean \pm SEM.

Analysis was performed using WinWCP 5.3.4 software (John Dempster, Strathclyde University, United Kingdom). Boltzmann curve fits were computed in MATLAB through non-linear least squares optimization.

\section{RESULTS}

\section{Enriched Pathways in FLS Cells After Cytokine Treatment}

RNA-seq detected 33251 transcripts and the full data are available on the EBI array express database with accession number: E-MTAB-7798. The top (highest FPKM) expressed 10 genes were similar between control and cytokine treated cells (Supplementary Tables S1, S2). Our first bioinformatic analysis tested the reproducibility of the $72 \mathrm{~h}, 10 \mathrm{ng} / \mathrm{ml}$ $\mathrm{TNF} \alpha+\operatorname{IL} 1 \beta$ treatment. We used discriminant analyses of 
A

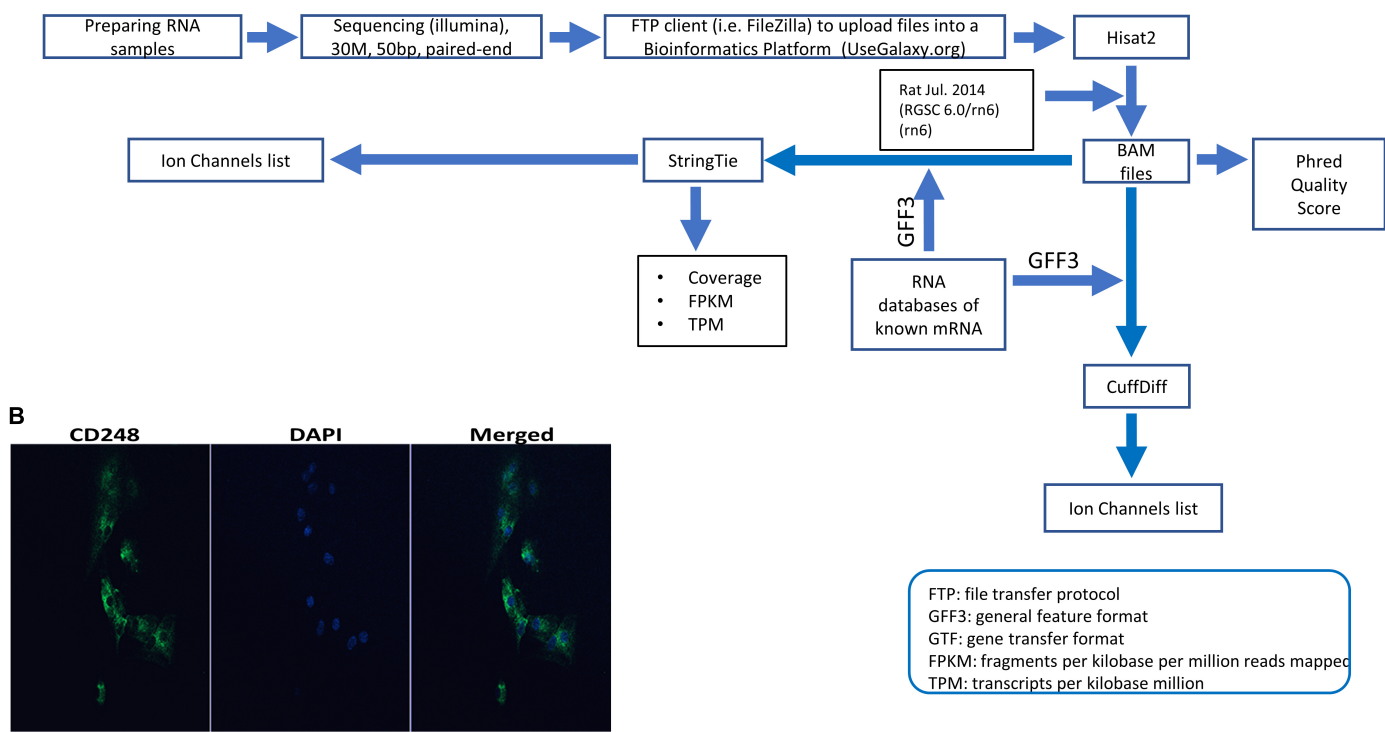

FIGURE 1 | Experimental pipeline and verification. (A) Schematic of the next generation sequencing (NGS) pipeline. RNA was extracted from synovial tissue from eight animals, were split into control and test groups and the test samples were treated with $10 \mathrm{ng} \mathrm{IL} 1 \beta$ and TNF $\alpha$ as described in the section "Materials and Methods." These eight samples sequenced with Illumina and raw data files were uploaded using a FTP client to a bioinformatics platform for analysis. Within the bioinformatics platform, reads were aligned/mapped with Hisat2 program using the reference genome Rat Jul. 2014 (RGSC 6.0/rn6) (rn6). The resulting BAM files were used to measure phred quality score for all samples. Also, BAM files along with an annotation file (Rat GFF3) to assemble mapped reads and quantify gene expression. Such assembly and quantification took place with StringTie and CuffDiff package/tool that generated gene abundance estimates and differentially expressed genes, respectively. After that, using several servers and a local custom-script in MATLAB software allowed us to filter the transcriptome for all known ion channel genes for further analysis (for example, see Tables 1, 2). (B) Expression of CD248 in FLS cells. Immunofluorescence FLS cells showing the FLS marker CD248. DAPI was used for nuclear counterstaining (see Supplementary Methods in Supplementary File S2 for details).

principal components (DAPC) with in the DAPC package to show good separation of the two populations (Figure 2); the genes primarily discriminating the treatment and control populations are largely those well established to be important for joint function, including several collagens and a matrix metallopeptidase (MMP2). Ingenuity pathway (IPA) analysis (Qiagen, United Kingdom) was then used to identify the upstream regulators of the global differential expression pattern. This analysis predicted the top two regulators to be TNF $\alpha$ and IL1 $\beta$ ( $p$-values $3 e-17$ and 6e-13, respectively), this is unsurprising since this was indeed the treatment regimen.

Figure 3 shows the canonical calcium signally pathway $(p<0.5 \mathrm{e}-7)$, which was enriched following cytokine treatment. In addition, the rheumatoid $(p<5 \mathrm{e}-13)$ and OA $(p<1 \mathrm{e}-$ 9) pathways and cellular movement and proliferation canonical pathways (predicted activation, $p<1 \mathrm{e}-13$ in both cases) were also enriched following cytokine treatment (data not shown). In all cases, $\mathrm{TNF} \alpha$ was determined to be the top causal agent, but four ion channels were also significant causal regulators (adjusted $p<0.05$ ) of the transcript-wide treatment changes; Clcn5, Trpv4, Trpv1, Kcnn4.

\section{Next Generation RNA Sequencing Analysis of Ion Channel Gene Expression}

Initial RNA-seq experiments were intended to give a transcriptome wide, unbiased, assessment of ion channel changes in cytokine treated FLS. We identified 190 channel genes, including porins, connexins and ion-channel isoform genes (including $\alpha$ - to $\varepsilon$-subunits), but excluded interacting proteins, other regulatory proteins and the so-called potassium tetramerization domain proteins. The top 50 genes, in terms of FPKM are given for control and cytokine treated datasets in Supplementary Tables S3, S4, respectively.

\section{Next Generation RNA Sequencing Ion Channel Differential Expression}

One of the key ion channels involved with regulation of FLS is the large calcium activated potassium channel (BK, Kcnmx) and it is notable that there was a reduction in expression of $\beta$-subunit $\mathrm{Kcnmb1/2}$ and appearance of Kcnmb3 after cytokine treatment. We further analyzed this family transcript by transcript for the 13 known (already annotated) splice variants of these channels; Kcnma1, Kcnmb1, Kcnmb2, Kcnmb3, Kcnmb4 (Figure 4C). The most abundantly expressed of all these transcripts is Kcnmal (ENSRNOT00000077671) with rather lower expression of any of the $\beta$-subunits and no detection of the one annotated Kcnmb4 variant. Following cytokine treatment expression of all of the detectable Kcnmal splice variants was higher, but there was a lower abundance of Kcnmb4.

In total, 20 ion channel genes, undetectable in control conditions became detectable or 'appeared' after cytokine treatment (Supplementary Table S5), of which, the top expressed 
A

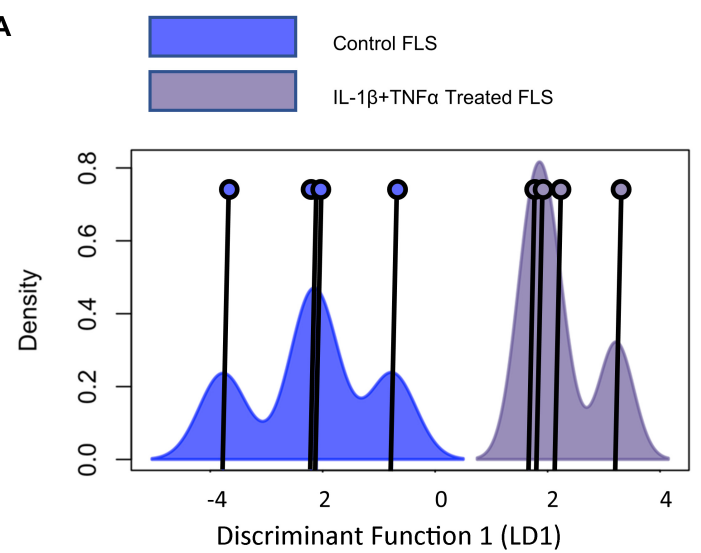

C
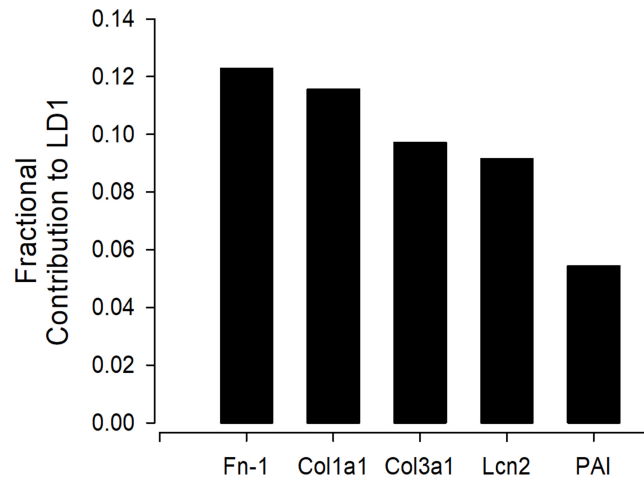

B
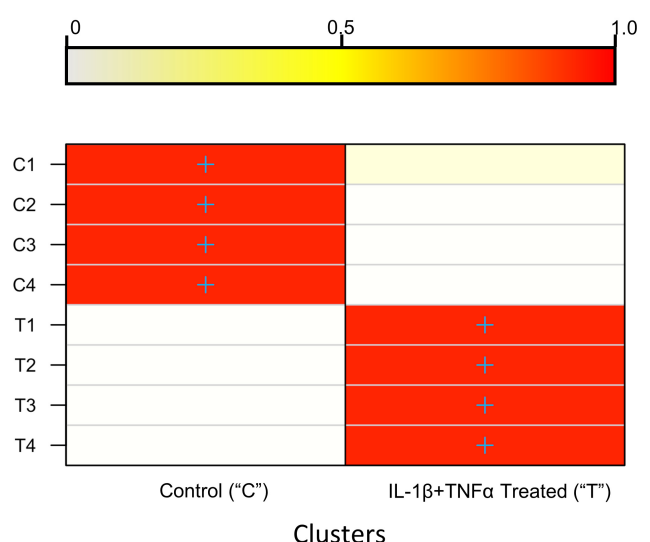

Gene contributions to Linear Discriminator 1 (LD1)

PAl Grem1 Mmp2 Thbs2 Cxcl12 Mgp

Gene Symbol

FIGURE 2 | Discriminant analyses of global IL-1 $\beta$ TNF $\alpha$ treatment effects. (A) Shows the kernel density plots of the discriminant component co-ordinates for the control and IL-1 $\beta / T N F \alpha$ treatment groups; co-ordinates on the $x$-axis and density on the $y$-axis; Individual co-ordinate center points are illustrated by the vertical line and circle. There is clear separation between control and cytokine treated FLS samples. (B) A graphical confusion matrix showing the actual group membership ( $y$-axis) and predicted cluster membership (on the $y$-axis). All groups are correctly clustered with greater than 0.9 probability. (C) The top 15 contributors to the linear discriminator function: Fn-1, fibronectin 1; Col1a1, collagen type I alpha 1 chain; Col3a1, collagen type III alpha 1 chain; Lcn2, lipocalin 2; PAl, serpine1; Grem1, gremlin 1; Mmp2, matrix metallopeptidase 2; Thbs2, thrombospondin 2; Cxcl12, C-X-C motif chemokine ligand 12; Mgp, matrix Gla protein; C3, complement C3; Col1a2, collagen type I alpha 2 chain; Sod2, superoxide dismutase 2; Lrp1, LDL receptor related protein 1; Col1a2, collagen type I alpha 2.

of these was Trpc3. Conversely, seven ion channel genes became undetectable or "disappeared" following cytokine treatment (Supplementary Table S6). Following cytokine treatment, we found an additional 15 genes to be down by $-1.5\left(\log _{2}\right)$ or more and 21 genes $1.5\left(\log _{2}\right)$ greater than control (Tables 1, 2, respectively). We used tissue from four animals for the NGS study each animal tissue split into test and control groups; the " $n$ " presented in the legends refers to the number of biological replicates (= animals).

\section{qPCR Verification of RNA Changes}

To add further support to the unbiased RNA-seq ion channel analysis we performed qPCR on sets of control and IL1 $\beta /$ TNF $\alpha$ treated FLS with panels of $\mathrm{Ca}^{2+}$-potassium channels (Kcnma1, Kcnn1, Kcnn2, Kcnn3) and other ion channel genes (Figure 4B). We did not have primers for all the potassium channel genes identified by next generation sequencing. Three potassium genes were differentially expressed; two voltage-gated potassium channels Kcna6 and Kcnc2significantly decreased $(p<0.05, n=4,4)$, whereas the large calcium potassium channel Kcnmal was upregulated $(p<0.05, n=4,4)$.

\section{Electrophysiology}

Neither RNA nor protein expression studies can confirm changes in functional ion channel expression or, functional changes resulting from post-translational changes, Furthermore, several different potassium channel isoforms were identified, of which some upregulated and some downregulated. Therefore, to investigate the effect of cytokine treatment on the electrophysiological fingerprint, we conducted functional assays of ion channel expression with patch-clamp electrophysiology. The primary changes observed in the more limited qRT-PCR data would predict over all loss of voltage-gated potassium ion channel activity and increase in the less voltage-dependent calcium activated potassium channels.

\section{Resting Membrane Potential}

Following cytokine treatment, the resting membrane potential of FLS decreased (depolarized) from $-48.6 \pm 1.7$ 


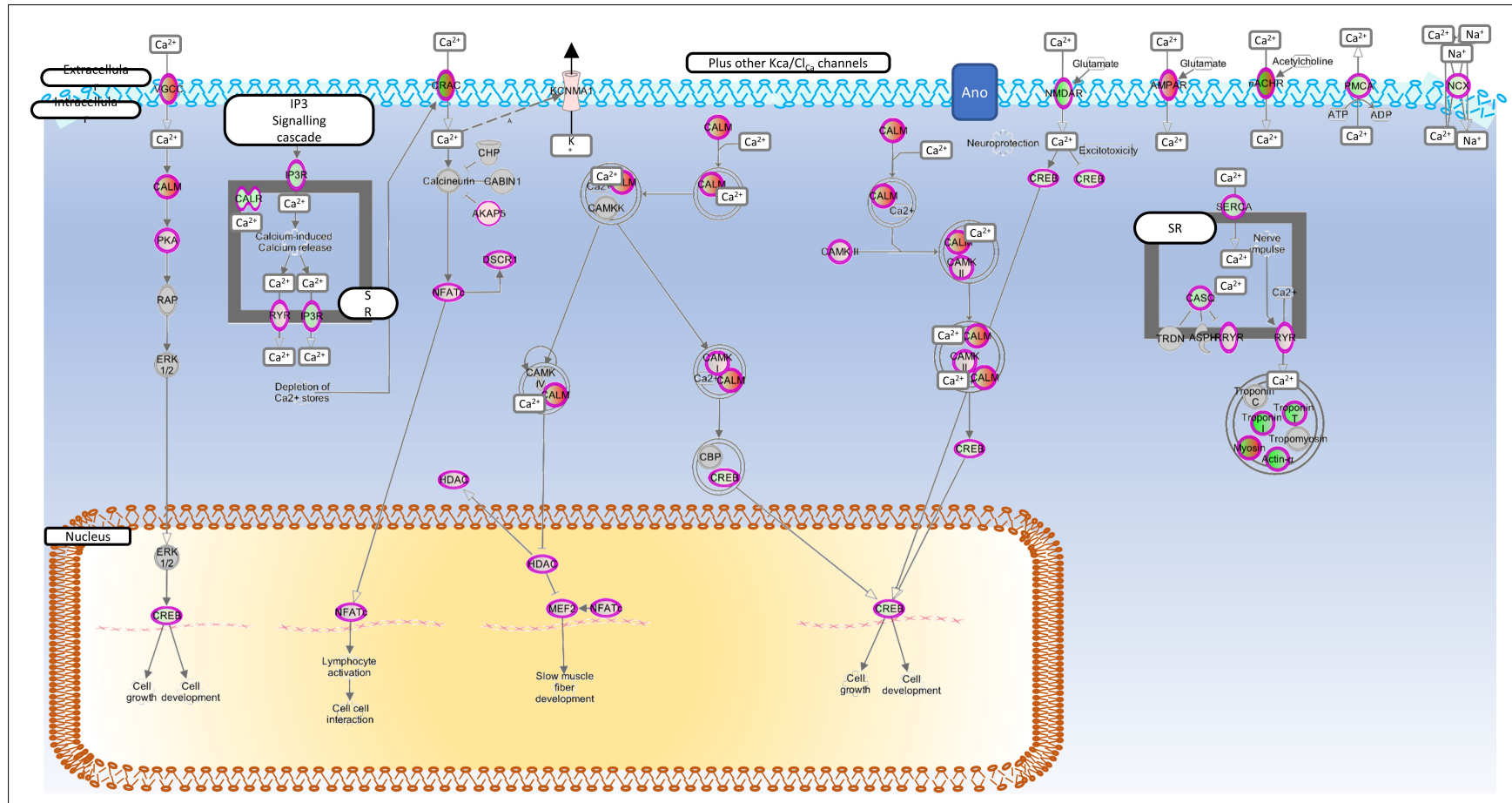

FIGURE 3 | Enriched calcium regulation pathway. Genes mapped to the calcium signaling canonical pathway by IPA. Red, increased expression; green, decreased expression (for interpretation of the references to color in the figure legend, please refer to the online version of this article).

to $-38.6 \pm 2.8 \mathrm{mV}$, junction potential corrected (data not shown, $p \leq 0.05$, unpaired $t$-test).

\section{Current Voltage Currents}

As seen in Figure 5A, some cells exhibited clear transient and sustained components whereas others exhibited only the sustained component of the current. We therefore analyzed the transient and sustained components of the current separately in all cases.

We found no overall change in the maximum amplitude of the transient current (Figure 5B), but the sustained current (Figure 5C) density, measured at $+20 \mathrm{mV}$ was decreased (12.5 $\pm 2.3 \mathrm{pA} / \mathrm{pF}$ to $3.8 \pm 0.8 \mathrm{pA} / \mathrm{pF}, n=24,20, p<0.05)$. There was no change in chord conductance measured at this potential $(271 \pm 45 \mathrm{pS} / \mathrm{pF}$ to $120 \pm 20 \mathrm{pS} / \mathrm{pF}, n=24,20)$. To characterize the nature of the conductance apparently inhibited by cytokine treatment we calculated the difference current for cytokine treatment (i.e., cytokine-treated current; Figure 5D). This revealed a strongly voltage-gated current with mid-point for activation $40 \pm 1.2 \mathrm{mV}$ and slope $17.6 \pm 1.2 \mathrm{mV}, n=25$.

\section{Pharmacological Modulation of Currents}

Despite the increase of KCNMA1 RNA in both qPCR and RNA-Seq our electrophysiological data show a reduced current density. To investigate if the maximum possible BK current is altered in cytokine treatment, we repeated our standard voltage protocol (above) in the presence of $1 \mu \mathrm{M}$ of the BK channel opener NS1619 and found a significant increase in current density in the presence of NS1619 in control cells (Figures 6A,C, $p \leq 0.05, n=9,6)$, we did not see an equivalent increase in the cytokine treated cells (Figures 6B,D). We then repeated this experiment with $1 \mu \mathrm{M}$ of the BK channel inhibitor paxilline. Untreated cell current density was significantly smaller in the presence of paxilline, but not significantly reduced in treated cells (Figures 6E,F).

\section{DISCUSSION}

In this study, we used an in vitro model of synovial cell inflammation to investigate the pathophysiology of cytokine induced synovitis. We have demonstrated that IL1 $\beta$ and $\mathrm{TNF} \alpha$ treatment of FLS cells resulted in profound changes in arthritic, inflammatory, and $\mathrm{Ca}^{2+}$ regulatory pathways similar to that reported in RA models. We found differential expression of several ion channels with transcriptomics and our electrophysiological experiments show a reduction of whole-cell current density.

\section{The Pathophysiological Validity of the $72 \mathrm{~h}$ IL1 $\beta$ and TNF $\alpha$ Model}

Treatment of joint tissue with $\mathrm{TNF} \alpha$ and IL1 $\beta$ cytokines is an established in vitro model of inflammatory arthritis with tissue typically exposed to between $10 \mathrm{ng} / \mathrm{ml}$ of $\mathrm{TNF} \alpha$ and IL1 $\beta$ for between 2 and 7 days. In the present study, we use the lower end of the concentration range, $10 \mathrm{ng}$ and treat for $72 \mathrm{~h}$ (De Ceuninck et al., 2004; Stevens et al., 2008, 2009; Pretzel et al., 2009; Williams et al., 2011; 


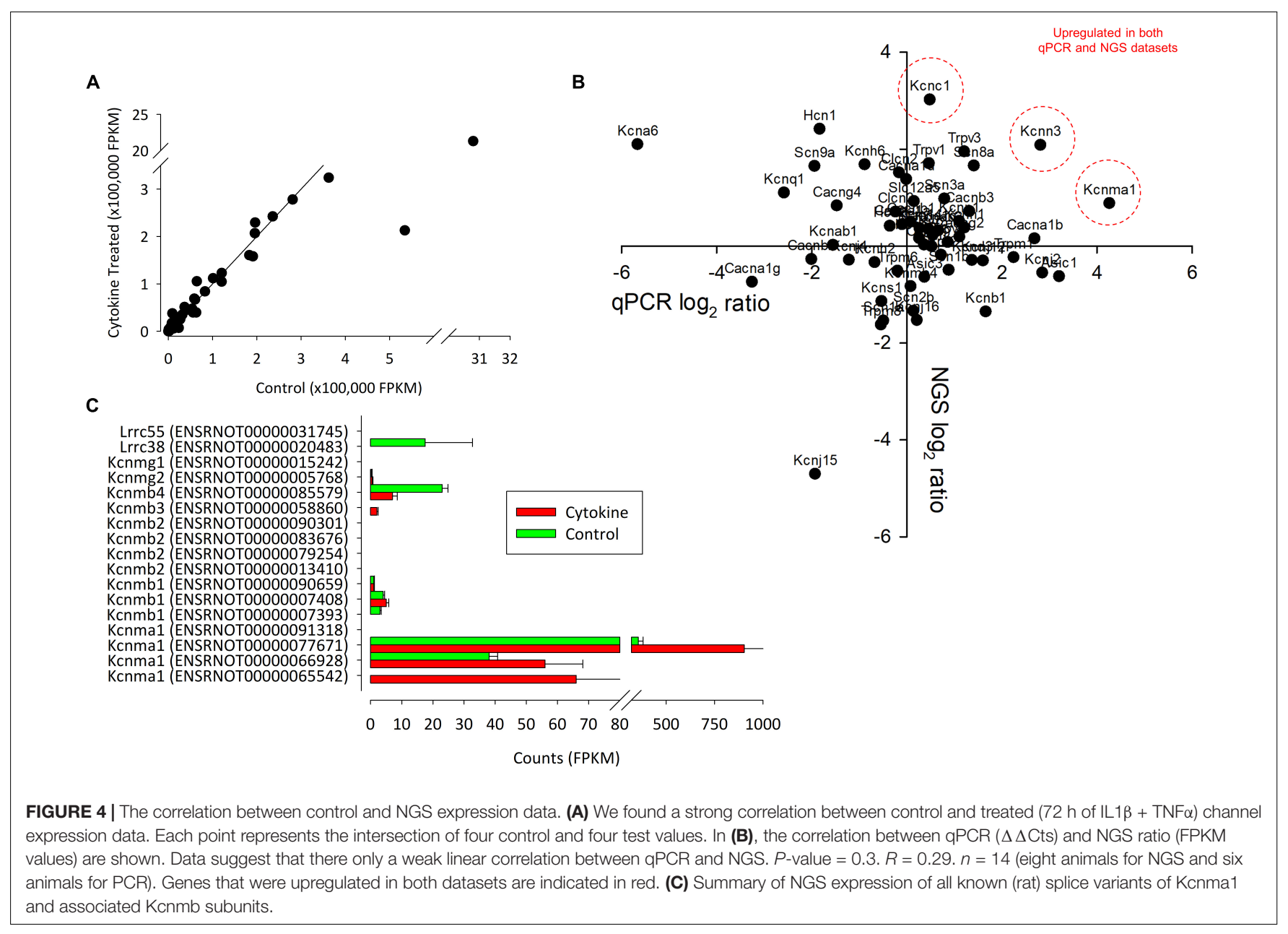

Williams, 2014). This regime is hypothesized to activate inflammatory pathways, but there will be no cytokine remaining by the time of the electrophysiological experiments that could cause confounding direct effects. We treated FLS cells with the pro-inflammatory cytokines IL1 $\beta$ and TNF $\alpha$ in order to understand the cellular changes that occur when these FLS are subjected to higher-than-normal levels of these cytokines in vivo, for example, in arthritis. This model has distinct advantages of 3Rs, consistency, reproducibility and allowing the investigation of distinct pathways in isolation but since it is an acute model it may lack some chronic features of in vivo models. Our transcriptome analysis demonstrated that pathways were activated in common with arthritis movement of cells, proliferation and both $\mathrm{RA}$ and OA. In an in vitro model of RA, Tanner et al. (2019) also showed up regulation of Kcnmal (message and protein) analogous to that observed with our $72 \mathrm{~h}$ cytokine treatment. Furthermore, more recent data suggests a correlation between FLS invasiveness and expression of the $\beta$-subunit (KCNMB3) in human samples of FLS from RA patients (Petho et al., 2016). Taken together with the changes in $\mathrm{Ca}^{2+}$ signaling, we show that our in vitro model captures several features of the inflammatory joint phenotype and that FLS have been "activated" as observed in animal models of arthritis.

Causal analysis is a relatively new mathematical technique that allows one to move from probability of agreement or simple correlation toward probability of causation in networks. The IPA implementation of this identified both IL1 $\beta$ and TNF $\alpha$ as master-regulators of the changes we observe and considering our experimental design included time matched controls, this strongly supports a suitable dosage and incubation time. Whilst both IL1 $\beta$ and TNF $\alpha$ were identified by IPA as "master regulators," TNF $\alpha$ transcriptome-wide causation was stronger than that of IL1 $\beta$. Interestingly, FLS cells harvested from RA patients exhibit a marked transient elevation of intracellular $\mathrm{Ca}^{2+}$ on exposure to TNF $\alpha$ (Yoo et al., 2006) raising the possibility that this could be the initial trigger for the resulting pathway changes. However, it should be noted that such a transient lasts less than a minute and in our study cells were challenged with cytokines $72 \mathrm{~h}$ prior to experiments. Furthermore, cells were replaced in cytokine-free medium for electrophysiology, so there would be no cytokine physically present at that time. Also, the previously reported $\mathrm{TNF} \alpha$ induced $\mathrm{Ca}^{2+}$ signal was only clear in FLS from RA; it was largely absent in FLS from OA patients and not investigated in FLS from healthy controls (Yoo et al., 2006). 
TABLE 1 | FLS channel gene RNA expression lower after cytokine (10 ng/ml TNF $\alpha$ and IL $1 \beta$ ) treatment.

\begin{tabular}{|c|c|c|}
\hline Gene & Official name & $\log _{2}(95 \% \mathrm{Cl})$ \\
\hline Kcnj15 & $\begin{array}{l}\text { Potassium inward rectified channel } \\
\text { subfamily j member } 15\end{array}$ & $-5.51(-9.57$ to -2.48$)$ \\
\hline Ano2 & Anoctamin 2 & $-2.59(-5.5$ to 0$)$ \\
\hline Kcnb1 & $\begin{array}{l}\text { Potassium voltage-gated channel subfamily } \\
\text { b member } 1\end{array}$ & $-2.44(-1.85$ to -1$)$ \\
\hline Kcnv2 & $\begin{array}{l}\text { Potassium voltage-gated channel modifier } \\
\text { subfamily v member } 2\end{array}$ & $-2.4(-4.85$ to 0$)$ \\
\hline Kcnip1 & $\begin{array}{l}\text { Potassium voltage-gated channel } \\
\text { interacting protein } 1\end{array}$ & $-2.36(-3.88$ to -0.88$)$ \\
\hline Kcnmb1 & $\begin{array}{l}\text { Potassium calcium-activated channel } \\
\text { subfamily m regulatory beta subunit } 1\end{array}$ & $-1.98(-3.28$ to 0.69$)$ \\
\hline Kons1 & $\begin{array}{l}\text { Potassium voltage-gated channel modifier } \\
\text { subfamily s member } 1\end{array}$ & $-1.88(-6.84$ to -0.42$)$ \\
\hline Kcnj8 & $\begin{array}{l}\text { Potassium inward rectifier j member } 8 \\
\text { (Kir6.1) }\end{array}$ & $-1.79(-4.71$ to 2.17$)$ \\
\hline Kcnd3 & $\begin{array}{l}\text { Potassium voltage-gated channel subfamily } \\
\text { d member } 3\end{array}$ & $-1.78(-2.63$ to 0.29$)$ \\
\hline Nalcn & Sodium leak channel, non-selective & $-1.77(-3.43$ to -0.85$)$ \\
\hline Clca2 & Chloride channel accessory 2 & $-1.76(-6.72$ to 0.65$)$ \\
\hline Kcne3 & $\begin{array}{l}\text { Potassium voltage-gated channel subfamily } \\
\text { e regulatory subunit } 3\end{array}$ & $-1.67(-1.84$ to -0.15$)$ \\
\hline Asic1 & Acid sensing ion channel subunit 1 & $-1.64(-6.44$ to 0$)$ \\
\hline Clcn4 & Chloride voltage-gated channel 4 & $-1.61(-2.61$ to -0.95$)$ \\
\hline Trpm8 & Trpm8 channel associated factor 1 & $-1.61(-2.09$ to -0.99$)$ \\
\hline
\end{tabular}

Qualification cytokine $\log _{2}$ (geometric mean) $<-1.5$ of control (= approximately $33 \%), n=4$ control and 4 cytokine treated samples (from four animals).

\section{Previous Studies of Differential Expression of Membrane Ion Channels in Synovium}

Until very recently, little was known of the FLS ion channel compliment (the "channelome") compared to that of the another central joint cell, the chondrocyte (Barrett-Jolley et al., 2010). One of the best-studied families of ion channels in FLS, however, is the $\mathrm{Ca}^{2+}$-activated potassium channel family. The high conductance member of this family, termed $\mathrm{BK}\left(K_{\mathrm{Ca}} 1.1\right.$ or KCNMA1) and the "intermediate" conductance member ("IK," or $K_{\mathrm{Ca}} 3.1$ ) are both expressed and have roles in invasive migration, proliferation, cytokine, and MMP release (Hu et al., 2012; Friebel et al., 2014). Interestingly, inhibitors of BK decrease the signs of joint degeneration in the pristane-induced arthritis model. These channels are therefore potential drug targets to protect against joint degeneration as well as being putative biomarkers. Whilst the BK channel $\beta$ - subunit (KCNMB1) was slightly increased in transcript abundance in the Lambert et al., 2014 data (similar seen by Huber et al., 2008), both of the two BK $\alpha$-subunit (KNMA1) probes on the chip exhibit small decreases in expression. It should be noted that the expression of BK channel $\beta$ - subunits confers modulation of ion channel activity, in many cases decreasing its sensitivity to, for example, $\mathrm{Ca}^{2+}$ ions (Lippiat et al., 2003; Mobasheri et al., 2012).

A recent study by Kondo et al. (2018) demonstrated that human FLS express high levels of both intermediate $\left(K_{\mathrm{Ca}} 3.1\right)$ and large $\left(\mathrm{BK} / K_{\mathrm{Ca}} 1.1 / \mathrm{KCNMA} 1\right) \mathrm{Ca}^{2+}$-activated potassium
TABLE 2 | FLS channel gene RNA expression increased after cytokine $(10 \mathrm{ng} / \mathrm{ml}$ TNF $\alpha$ and IL $1 \beta$ ) treatment.

\begin{tabular}{|c|c|c|}
\hline Gene ID & Official name & $\log _{2}(95 \% \mathrm{Cl})$ \\
\hline Kcnc1 & $\begin{array}{l}\text { Potassium voltage-gated channel subfamily c } \\
\text { member } 1\end{array}$ & 4.32 (0.68 to 5.93 ) \\
\hline Kcnc3 & $\begin{array}{l}\text { Potassium voltage-gated channel subfamily c } \\
\text { member } 3\end{array}$ & 3.46 (0.76 to 5.94$)$ \\
\hline Trpc3 & $\begin{array}{l}\text { Transient receptor potential cation channel } \\
\text { subfamily c member } 3\end{array}$ & 3.06 (3.73 to 6.5$)$ \\
\hline Catsper3 & Cation channel sperm associated 3 & 2.83 (0.14 to 5.75$)$ \\
\hline Kcng3 & $\begin{array}{l}\text { Potassium voltage-gated channel modifier } \\
\text { subfamily g member } 3\end{array}$ & 2.81 (2.77 to 6.65$)$ \\
\hline Tmc7 & Transmembrane channel like 7 & 2.77 (1.99 to 5.53$)$ \\
\hline Gjc3 & Gap junction protein gamma 3 & 2.75 (0.03 to 4.35$)$ \\
\hline Scnn1g & Sodium channel epithelial 1 gamma subunit & 2.56 (2.77 to 5.45$)$ \\
\hline Asic2 & Acid sensing ion channel subunit 2 & 2.52 (0.66 to 4.65$)$ \\
\hline Kcnmb3 & $\begin{array}{l}\text { Potassium calcium-activated channel subfamily } \\
\text { m regulatory beta subunit } 3\end{array}$ & 2.34 (0 to 4.73$)$ \\
\hline Cracr2a & Calcium release activated channel regulator $2 \mathrm{a}$ & 2.32 (0.01 to 1.96$)$ \\
\hline Kcnn3 & $\begin{array}{l}\text { Potassium calcium-activated channel subfamily } \\
\mathrm{n} \text { member } 3\end{array}$ & 2.07 (0.57 to 4.09$)$ \\
\hline Tmc4 & Transmembrane channel like 4 & $1.94(0.27$ to 2.47$)$ \\
\hline Asic4 & $\begin{array}{l}\text { Acid sensing ion channel subunit family } \\
\text { member } 4\end{array}$ & 1.75 (0.52 to 2.76$)$ \\
\hline Kcnj11 & Potassium inward rectifier j member 11 (Kir6.2) & 1.74 (0 to 6.56$)$ \\
\hline Trpv6 & $\begin{array}{l}\text { Transient receptor potential cation channel } \\
\text { subfamily v member } 6\end{array}$ & $1.7(0.01$ to 5.43$)$ \\
\hline Hven1 & Hydrogen voltage gated channel 1 & 1.69 (0.98 to 2.84$)$ \\
\hline Trpv1 & $\begin{array}{l}\text { Transient receptor potential cation channel } \\
\text { subfamily v member } 1\end{array}$ & 1.61 (0.98 to 2.07$)$ \\
\hline Kcnk7 & $\begin{array}{l}\text { Potassium two pore domain channel subfamily } \\
\mathrm{k} \text { member } 7\end{array}$ & $1.6(-1.85$ to 1.03$)$ \\
\hline Cacna1d & $\begin{array}{l}\text { Calcium voltage-gated channel subunit alpha1 } \\
\text { d }\end{array}$ & 1.57 (0.32 to 2.09 ) \\
\hline Asic5 & $\begin{array}{l}\text { Acid sensing ion channel subunit family } \\
\text { member } 5\end{array}$ & 1.55 (0 to 5.78$)$ \\
\hline
\end{tabular}

Qualification cytokine $\log _{2}$ (geometric mean) > 1.5 of control (= approximately $300 \%), n=4$ control and 4 cytokine treated samples (from four animals).

channels. The other most highly expressed ion channels identified by Kondo et al. (2018) were KCNK2, ANO6, ANO10, and KCNK6. KCNK2/6 are members of the two-pore-domain potassium channel family and are particularly thought of as molecular sensors, whereas the ANO (anoctamin) channels are members of the large chloride channel family. This family is relatively understudied compared to potassium channels, but ANO6 (TMEM16F) is, interestingly, thought to be a $\mathrm{Ca}^{2+}$. activated chloride channel as well as a lipid "scramblase" (Scudieri et al., 2015), therefore, likely to be activated in parallel to $\mathrm{Ca}^{2+}$-activated potassium channels.

\section{Changes in Ion Channel Currents in the Present Study}

The phenotype of FLS current recorded by whole-cell patch clamp was quite variable in terms of the presence of transient and sustained components of current, as seen in Figure 5. We found no significant changes in the transient phase of current and therefore, we focused on the sustained component of voltage 


\section{A}
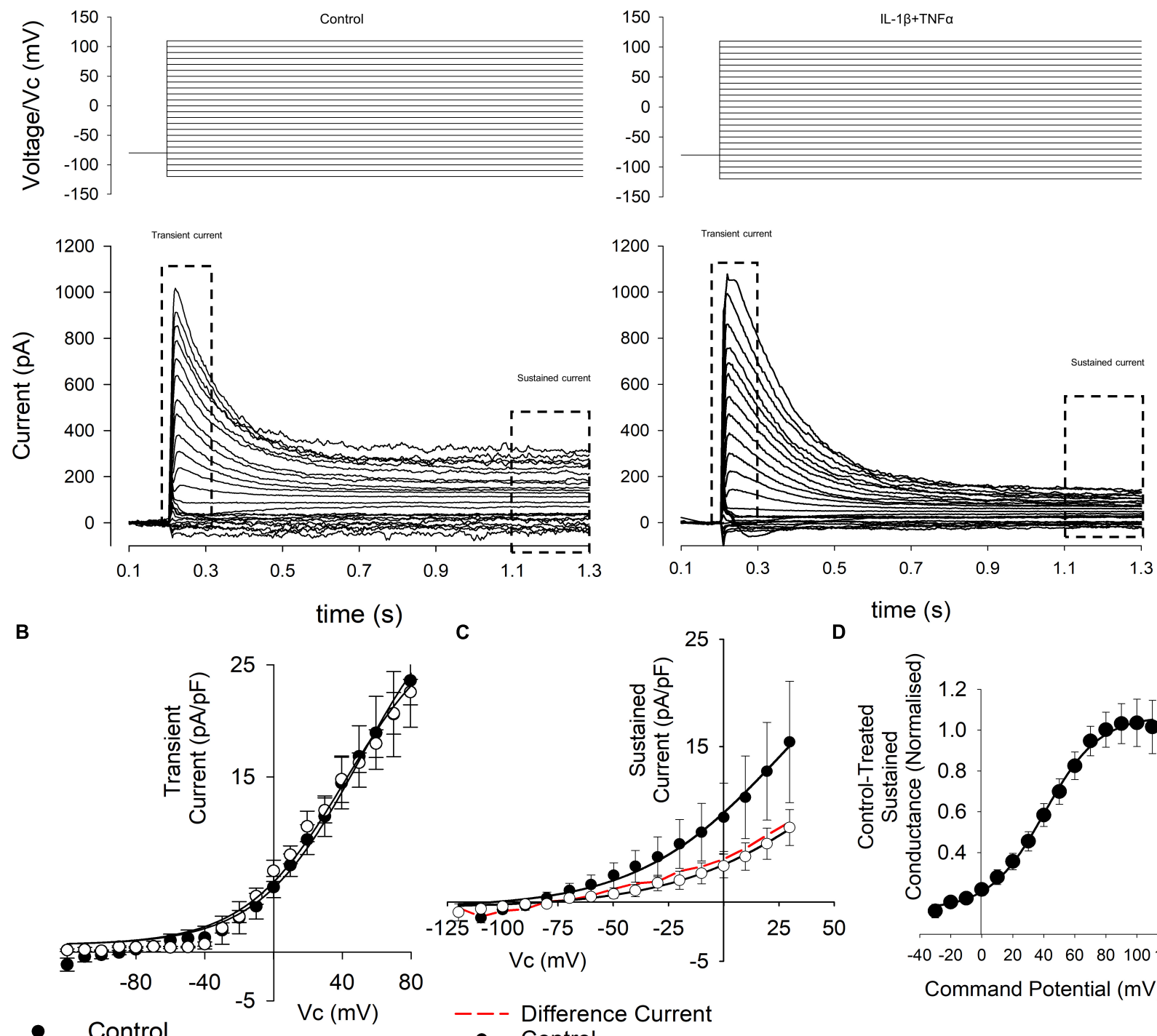

C

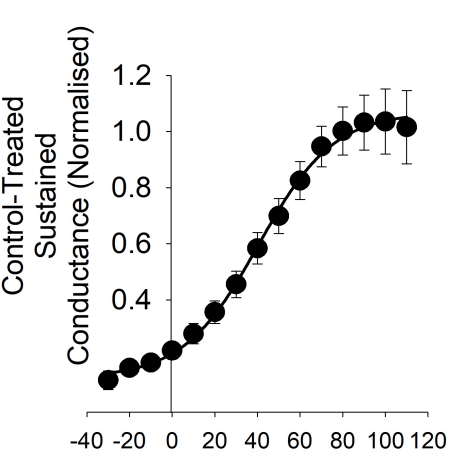

Command Potential $(\mathrm{mV})$

- Control

$\circ \quad 111 \beta+$ TNF $\alpha$ Treated

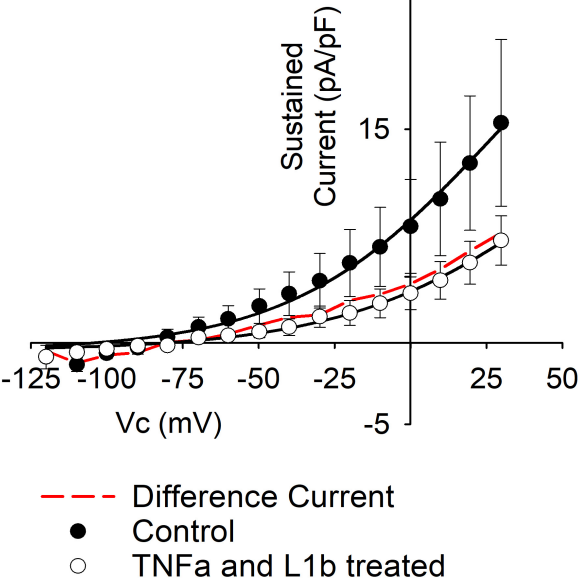

FIGURE 5 | Whole-cell voltage-gated currents from control and cytokine treated FLS. (A) Top panels show the voltage step protocols and the evoked currents are shown below for control (left) and IL1 $\beta+$ TNF $\alpha$ (right) conditions. Note that FLS exhibit both transient and sustained currents. These phases of current were then analyzed separately as indicated. (B) Current-voltage curves (left) from the transient currents recorded in a number or experiments such as that illustrated in (A). There was no significant difference between control and treated transient current density. Data points are shown as mean \pm SEM $(n=18$ for control and $n=11$ for IL1 $\beta+T N F \alpha)$. (C) Current-voltage curves from the sustained currents recorded in a number or experiments such as that illustrated in (A). The red line in the current-voltage curve is the difference current for control-cytokine treated. (D) Difference conductance-voltage curve for the cytokine difference current shown in (C). The line is fit with a Boltzmann, see text.

activated currents that would be expected to include BK activity if it was present. Although we found a significant increase in RNA expression of the BK $\alpha$-subunit gene, Kcnma1, following cytokine treatment (by qPCR), there was a decrease in over-all current density of the sustained current. To characterize the voltagegated characteristics of the current lost after cytokine treatment we subtracted IV curves following cytokine treatment from the control IV curves and transformed this to a conductance-voltage curve. Since this curve fully saturated, we were able to fit it with a Boltzmann curve and derive the midpoint for activation; $+40 \mathrm{mV}$. This is rather positive to most voltage-gated potassium channels, the most "positive" of which (Kcnbx/Kcncx) have activation mid-points in the +10 to $+20 \mathrm{mV}$ range (Coetzee et al., 1999). This cytokine sensitive conductance could be an ensemble average of a number of different ion channel changes, including increase of some and decrease of others. It could also be a BK current under conditions of low intracellular $\mathrm{Ca}^{2+}$ (Cui et al., 1997, 2009; Coetzee et al., 1999; Contreras et al., 2012), 


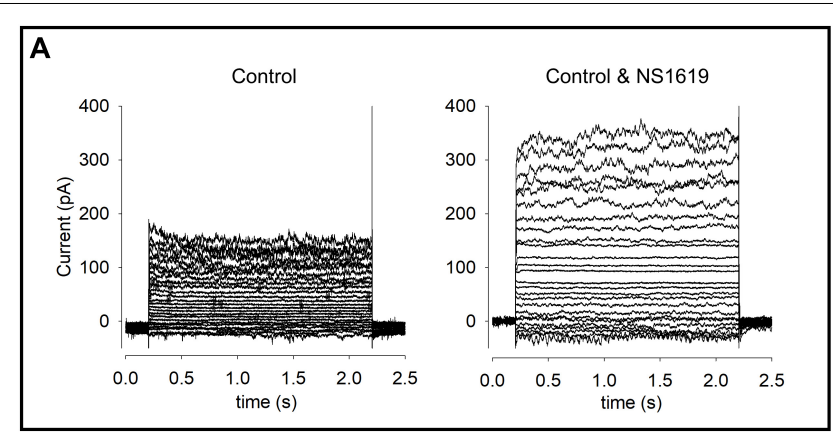

C

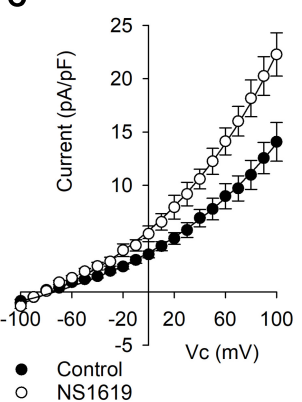

D

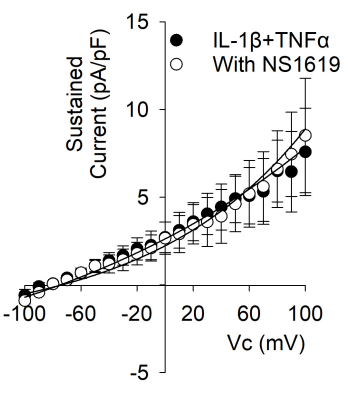

E

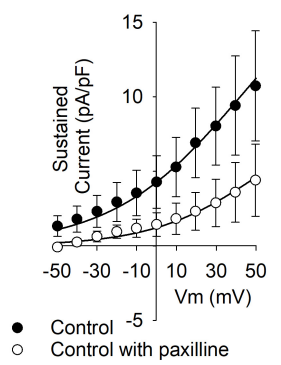

$\mathrm{IL}-1 \beta+\mathrm{TNF} \alpha$

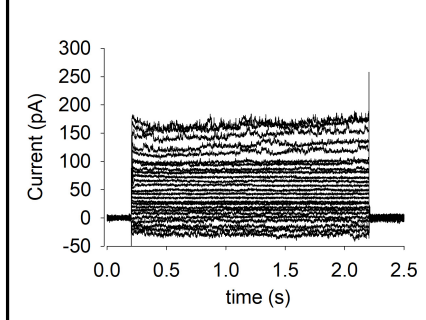

$\mathbf{F}$
IL-1 $\beta+T N F \alpha \& N S 1619$

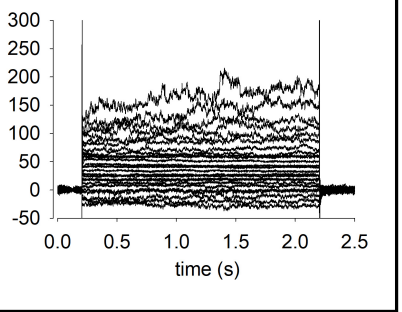

G
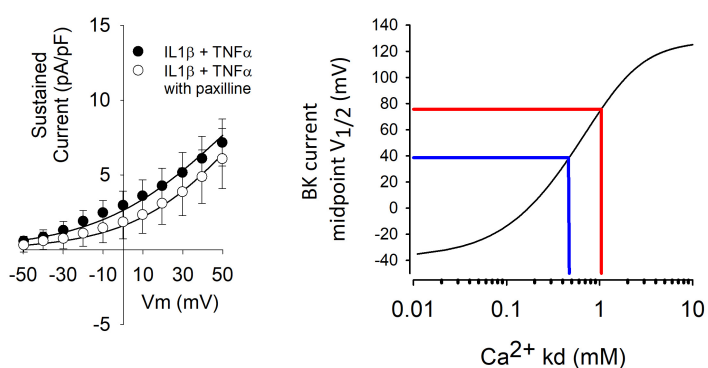

FIGURE 6 | Effects of BK channel drugs on FLS whole-cell currents. (A) Representative examples of untreated (control) cells before (left) and in the presence of $1 \mu \mathrm{M}$ of the BK channel opener NS1619 (left). Voltage protocols as shown in Figure 5. (B) Representative raw example current families of cytokine (10 ng/ml $\mathrm{IL} 1 \beta+\mathrm{TNF} \alpha$ ) treated cells in the absence (left) and presence (right) of $1 \mu \mathrm{M}$ NS1619. (C) Current-voltage curves from a number of control FLS cells such as that shown in (A). Current is significantly greater in the presence of NS1619, $p<0.05, n=9$ and 6. (D) Current-voltage curves for a number of treated FLS cells such as that shown in (B). These two curves are not significantly different from each other $n=6$ and 6 . (E) Current-voltage curves from a number of control FLS cells treated with and without paxilline; there is a significant decrease in paxilline current $p<0.05 n=13,5)$, but (F) there was no significant different of current density in the presence of the BK inhibitor paxilline following cytokine treatment $(n=6,12)$. (G) Numerical simulation of data from Clark et al. (2017) model. To quantify the degree of change of BK channel modulation apparently taking place with this treatment we used the model of verbatim with the exception that we varied the inherent BK channel $\mathrm{Ca}^{2+}$ sensitivity parameter $K d$. In this simulation, the independent variable $K d$ is plotted on the $x$-axis and the predicted $B K$ current midpoint $\left(V_{1 / 2}\right)$ is plotted on the $y$-axis. In blue, we have added hypothetical midpoints of $40 \mathrm{mV}$ and $80 \mathrm{mV}$ representing a hypothetical shift in $40 \mathrm{mV}$ by cytokine treatment. The complete MATLAB code for this simulation is included in the Supplementary File S1.

but, since the true local concentration of intracellular $\mathrm{Ca}^{2+}$ is unknown, this is difficult to assess. $\mathrm{V}_{1 / 2}$ for the $\mathrm{BK}$ channel in the virtual absence of $\mathrm{Ca}^{2+}$ can be much higher, for example 200-300 mV (Bao and Cox, 2005; Orio and Latorre, 2005; Wang and Brenner, 2006). The value of this parameter also depends on the nature of the co-expressed $\beta$-subunit (Coetzee et al., 1999; Contreras et al., 2012). $\mathrm{V}_{1 / 2}$ is typically shifted to the left in the presence of beta subunits (Brenner, 2014). In our transcript data (Figure 4C), we show a range of $\mathrm{BK}$ transcripts including the Lrrcx subunits, but none, on their own, show significant alteration by treatment. Note that with experimentally elevated intracellular $\mathrm{Ca}^{2+}$ concentration these would likely lie well to the left of where they lay in our experiments. In our experiments we included $5 \mathrm{mM}$ EGTA, which allows for the $\mathrm{Ca}^{2+}$-activation of BK channels so long as they are physically close to the $\mathrm{Ca}^{2+}$ source (Fakler and Adelman, 2008). Functional coupling between $\mathrm{BK}$ and the $\mathrm{Ca}^{2+}$ source appears a common phenomenon (Fakler and Adelman, 2008); we also showed this with a coupling between TRPV4 channels and $K_{\mathrm{Ca}}$ channels previously in neurones (Feetham et al., 2015) and it has also been shown in smooth muscle cells too (Nilius and Droogmans, 2001). Increasing, or attempting to "clamp" intracellular $\mathrm{Ca}^{2+}$ before investigating
BK channels would be tempting, but this could cause greater constitutive activation of BK and mask a physiological coupling.

Our electrophysiological experiments also demonstrated significantly more depolarized resting membrane potentials in cytokine treated cells. This could result from loss of constitutive potassium or chloride conductances, but equally it could result from the elevation of the non-specific or $\mathrm{Na}^{+}$selective or ion channels such as Trpc3 or Asic2, etc. (Table 2).

The BK pharmacological activator (NS1619) and inhibitor (paxilline) both had the expected effects (increase and decrease of current density, respectively) in the untreated FLS but neither had a significant effect. This is surprising in the light of the Tanner et al. (2015) data showing that paxilline ameliorate development joint degeneration in a model of RA and the continued effectiveness of paxilline in FLS from RA patients (Petho et al., 2016). One possible explanation could be differences in transcript expression between strains as has been observed with ion channels previously (Kunert-Keil et al., 2006). Our RNA data showed a clear shift from RNA-expression of $\beta 1$ (and $\beta 2$ ) subunits to $\beta 3$ and sensitivity to voltage, calcium and some drugs is well-known to be conveyed by co-expression of the $\beta$ subunits (McManus et al., 1995; Uebele et al., 2000; Yang 
et al., 2009). However, neither paxilline nor NS1619 themselves are thought to be influenced by the $\beta$-subunit; paxilline acts as a closed channel blocker (Zhou and Lingle, 2014) whereas NS1619 opens the BK channel by binding to the KCNMA1 S6/RCK linker and is effective in some splice variants, but not others (Soom et al., 2008; Gessner et al., 2012). In humans there are 93 known s[lice variants of KCNMA1, but there are only four in rats listed on ENSEMBL (Zerbino et al., 2018). Figure 4 shows the relative transcript expression for Kcnmal. The most abundant transcript (ENSRNOT00000077671 Kcnma1-203) is present in both conditions. None of the Kcnma1 transcripts decrease with cytokine so it seems unlikely (but not impossible) that pharmacological changes result directly from splice variant switching. Note that the one known transcript that was not detected is the truncated transcript Kcnma1-204 (ENSRNOT00000091318). The lack of effect of NS1619 and paxilline after cytokine treatment could be also be secondary to changes in $\beta$-subunits or intracellular $\mathrm{Ca}^{2+}$ in microdomains or some unknown reason leaving insufficient residual functional $\mathrm{BK}$ activity to be noticeably modulated. The simple $\left(\mathrm{K}^{+}\right.$channel focused) FLS electrophysiological model of Clark allows us to use numerical simulation to estimate the change in $\mathrm{BK}$ channel $\mathrm{Ca}^{2+}$ that would be required to shift a BK conductance voltage curve by about $+40 \mathrm{mV}$ and largely leave the cells virtually free of measurable BK current (Figure 6G). We find that retaining all the parameters of Clark et al. (2017) except the $\mathrm{Ca}^{2+} K d$ itself, such data would be the equivalent to increasing $K d$ from $0.46 \mu \mathrm{M}$ to approximately $1.05 \mu \mathrm{M}$. The upstream pathway (beyond the activation of the cytokine pathway including $\mathrm{NF \kappa B}$, etc.) for these changes is difficult to identify from our data, especially since there are relatively few ion channel interaction data in the IPA databases. It is notable, however, that there were significant changes in the calcium signaling pathway (Figure 3) and so it is possible that change in calcium activated potassium channel expression follows this, by way of compensatory expression. The lack of apparent effect of paxilline could also be technical. For example, there was considerable variability between cells and we compared population means rather than pairing each cell with and without paxilline increasing the risk of a type II error.

\section{Role of Ion Channels in Pro-inflammatory Cytokine Production and Secretion}

Ion channels are involved not just in the response to cytokines, but can also contribute to their production. For example, ionotropic NMDA and kainite glutamate receptors contribute to synovial inflammation by increasing expression of the inflammatory cytokine IL-6 (Flood et al., 2007) and nicotinic acetylcholine receptor activation reduces the synovial production of IL-6, IL-8, TNF $\alpha$, and several other cytokines (Waldburger et al., 2008; van Maanen et al., 2009). P2X7 is an established conduit for release of mediators such as IL1 $\beta$ (Mortaz et al., 2012). We saw little P2X7 RNA, but there is evidence that in chondrocytes P2X1, may sub serve the same function (Varani et al., 2008) and we detected
RNA for this channel only after cytokine treatment. In a previous report, inhibition of the small $\mathrm{Ca}^{2+}$ activated potassium ion channel decreased the production of cytokines IL-6, IL8 , and MCP1 in response to TGF-1 $\beta$, but they did not examine secretion of IL1 $\beta$ or TNF $\alpha$ (Friebel et al., 2014). In other-words activation of $\mathrm{Ca}^{2+}$ potassium ion channels is essentially a secretion trigger. This result is somewhat counter intuitive since one would expect activation of a potassium channel to hyperpolarize and decrease secretion. One possible explanation is that activation of $\mathrm{Ca}^{2+}$ potassium ion channels draws in additional $\mathrm{Ca}^{2+}$ by increasing the driving force for $\mathrm{Ca}^{2+}$ entry.

$$
C a^{2+} \text { entry } \alpha(V m-E q \mathrm{Ca} 2+)
$$

Where negative values are equivalent to inward driving force for $\mathrm{Ca}^{2+}, V m$ is the membrane potential and $E q_{\mathrm{Ca} 2+}$ is the equilibrium potential for $\mathrm{Ca}^{2+}$.

\section{CONCLUSION}

To our knowledge, this is the first report using a combined NGS and patch-clamp electrophysiological approach to understanding the control of potassium channels in inflammation in joint tissues. We found an increased RNA expression of the BK potassium gene Kcnmal, but the constitutive activity of the channel was not increased. The decreased sensitivity to voltage activation and to drugs could be explained by a switch the RNA expression of $\beta$-subunits $\mathrm{KcnmB1}, 2$, and 3.

\section{DATA AVAILABILITY STATEMENT}

The datasets generated for this study can be found in the https:// www.ebi.ac.uk/arrayexpress/experiments/E-MTAB-7798/.

\section{ETHICS STATEMENT}

The animal study was reviewed and approved by the University of Liverpool Veterinary Ethics Committee.

\section{AUTHOR CONTRIBUTIONS}

All authors have conceptualized and designed the study, and analyzed and interpreted the data. RB-J, FO, and KK drafted the manuscript. All authors have critically revised the manuscript for important intellectual content. All authors have finally approved the manuscript. RB-J, AM, and $\mathrm{OH}$ obtained the funding.

\section{FUNDING}

This study was funded by the European Union's Seventh Framework Programme (EU FP7; grant agreement No. 305815), 
BBSRC (BB/N003020/1), The University of Liverpool, and King Abdulaziz University, Jeddah, Saudi Arabia.

\section{ACKNOWLEDGMENTS}

For funding, the authors would like to thank the European Union's Seventh Framework Programme for research, technological development, and demonstration (Grant

\section{REFERENCES}

Afgan, E., Baker, D., Batut, B., van den Beek, M., Bouvier, D., Cech, M., et al. (2018). The Galaxy platform for accessible, reproducible and collaborative biomedical analyses: 2018 update. Nucleic Acids Res. 46, W537-W544. doi: 10.1093/nar/ gky379

Bao, L., and Cox, D. H. (2005). Gating and ionic currents reveal how the BKCa channel's Ca2+ sensitivity is enhanced by its beta1 subunit. J. Gen. Physiol. 126, 393-412. doi: 10.1085/jgp.200509346

Barrett-Jolley, R., Lewis, R., Fallman, R., and Mobasheri, A. (2010). The emerging chondrocyte channelome. Front. Physiol. 1:135. doi: 10.3389/fphys.2010.00135

Bartok, B., and Firestein, G. S. (2010). Fibroblast-like synoviocytes: key effector cells in rheumatoid arthritis. Immunol. Rev. 233, 233-255. doi: 10.1111/j.0105-2896. 2009.00859.x

Berenbaum, F. (2013). Osteoarthritis as an inflammatory disease (osteoarthritis is not osteoarthrosis!). Osteoarthr. Cartil. 21, 16-21. doi: 10.1016/j.joca.2012.1 1.012

Brenner, R. (2014). Knockout of the BK $\beta 2$ subunit reveals the importance of accessorizing your channel. J. Gen. Physiol. 144, 351-356. doi: 10.1085/jgp. 201411291

Clark, R. B., Schmidt, T. A., Sachse, F. B., Boyle, D., Firestein, G. S., and Giles, W. R. (2017). Cellular electrophysiological principles that modulate secretion from synovial fibroblasts. J. Physiol. 595, 635-645. doi: 10.1113/JP270209

Coetzee, W. A., Amarillo, Y., Chiu, J., Chow, A., Lau, D., McCormack, T., et al. (1999). Molecular diversity of K+ channels. Ann. N. Y. Acad. Sci. 868, 233-285.

Contreras, G. F., Neely, A., Alvarez, O., Gonzalez, C., and Latorre, R. (2012). Modulation of BK channel voltage gating by different auxiliary beta subunits. Proc. Natl.Acad. Sci. U.S.A. 109, 18991-18996. doi: 10.1073/pnas.1216953109

Cui, J., Cox, D. H., and Aldrich, R. W. (1997). Intrinsic voltage dependence and $\mathrm{Ca} 2+$ regulation of mslo large conductance Ca-activated $\mathrm{K}+$ channels. J. Gen. Physiol. 109, 647-673. doi: 10.1085/jgp.109.5.647

Cui, J., Yang, H., and Lee, U. S. (2009). Molecular mechanisms of BK channel activation. Cell Mol. Life Sci. 66, 852-875. doi: 10.1007/s00018-008-8609-x

De Ceuninck, F., Dassencourt, L., and Anract, P. (2004). The inflammatory side of human chondrocytes unveiled by antibody microarrays. Biochem. Biophys. Res. Commun. 323, 960-969. doi: 10.1016/j.bbrc.2004.08.184

Fakler, B., and Adelman, J. P. (2008). Control of K(Ca) channels by calcium nano/microdomains. Neuron 59, 873-881. doi: 10.1016/j.neuron.2008.09.001

Feetham, C. H., Nunn, N., Lewis, R., Dart, C., and Barrett-Jolley, R. (2015). TRPV4 and $\mathrm{KCa}$ ion channels functionally couple as osmosensors in the paraventricular nucleus. Br. J. Pharmacol. 172, 1753-1768. doi: 10.1111/bph.13023

Fernandez-Madrid, F., Karvonen, R. L., Teitge, R. A., Miller, P. R., An, T., and Negendank, W. G. (1995). Synovial thickening detected by MR imaging in osteoarthritis of the knee confirmed by biopsy as synovitis. Magn. Reson. Imaging 13, 177-183. doi: 10.1016/0730-725X(94)00119- N

Flood, S., Parri, R., Williams, A., Duance, V., and Mason, D. (2007). Modulation of interleukin- 6 and matrix metalloproteinase 2 expression in human fibroblastlike synoviocytes by functional ionotropic glutamate receptors. Arthritis Rheum 56, 2523-2534. doi: 10.1002/art.22829

Friebel, K., Schonherr, R., Kinne, R. W., and Kunisch, E. (2014). Functional role of the KCa3.1 potassium channel in synovial fibroblasts from rheumatoid arthritis patients. J. Cell Physiol. 230, 1677-1688. doi: 10.1002/jcp.24924

Gessner, G., Cui, Y. M., Otani, Y., Ohwada, T., Soom, M., Hoshi, T., et al. (2012). Molecular mechanism of pharmacological activation of BK channels. Proc. Natl. Acad. Sci. U.S.A. 109, 3552-3557. doi: 10.1073/pnas.1114321109 agreement no. 305815) and King Abdulaziz University, Jeddah, Saudi Arabia.

\section{SUPPLEMENTARY MATERIAL}

The Supplementary Material for this article can be found online at: https://www.frontiersin.org/articles/10.3389/fphys. 2020.00226/full\#supplementary-material

Grubb, B. D. (2004). Activation of sensory neurons in the arthritic joint. Novartis Found Symp. 260, 28-36discussion 36- 48, 277-279.

Hu, X., Laragione, T., Sun, L., Koshy, S., Jones, K. R., Ismailov, I. I., et al. (2012). KCa1.1 potassium channels regulate key proinflammatory and invasive properties of fibroblast-like synoviocytes in rheumatoid arthritis. J. Biol. Chem. 287, 4014-4022. doi: 10.1074/jbc.M111.312264

Huber, R., Hummert, C., Gausmann, U., Pohlers, D., Koczan, D., Guthke, R., et al. (2008). Identification of intra-group, inter-individual, and gene-specific variances in mrna expression profiles in the rheumatoid arthritis synovial membrane. Arthritis Res. Ther. 10:R98. doi: 10.1186/ar2485

Kahlenberg, J. M., and Fox, D. A. (2011). Advances in the medical treatment of rheumatoid arthritis. Hand Clin. 27, 11-20. doi: 10.1016/j.hcl.2010.09.002

Kondo, C., Clark, R. B., Kim, T. Y., Belke, D., Banderali, U., Szerencsei, R. T., et al. (2018). Atp triggers a robust intracellular $\left[\mathrm{ca}^{2+}\right]$-mediated signalling pathway in human synovial fibroblasts. Exp. Physiol. 103, 1101-1122. doi: 10. 1113/EP086851

Kumahashi, N., Naitou, K., Nishi, H., Oae, K., Watanabe, Y., Kuwata, S., et al. (2011). Correlation of changes in pain intensity with synovial fluid adenosine triphosphate levels after treatment of patients with osteoarthritis of the knee with high-molecular-weight hyaluronic acid. Knee 18, 160-164. doi: 10.1016/j. knee.2010.04.013

Kunert-Keil, C., Bisping, F., Kruger, J., and Brinkmeier, H. (2006). Tissuespecific expression of TRP channel genes in the mouse and its variation in three different mouse strains. Bmc Genomics 7:159. doi: 10.1186/1471-21647-159

Lambert, C., Dubuc, J.-E., Montell, E., Vergés, J., Munaut, C., Noël, A., et al. (2014). Gene expression pattern of cells from inflamed and normal areas of osteoarthritis synovial membrane. Arthritis Rheumatol. 66, 960-968. doi: 10. 1002/art.38315

Large, R. J., Hollywood, M. A., Sergeant, G. P., Thornbury, K. D., Bourke, S., Levick, J. R., et al. (2010). Ionic currents in intimal cultured synoviocytes from the rabbit. Am. J. Physiol. Cell Physiol. 299, C1180-C1194. doi: 10.1152/ajpcell. 00028.2010

Lewis, R., Feetham, C. H., Gentles, L., Penny, J., Tregilgas, L., Tohami, W., et al. (2013). Benzamil sensitive ion channels contribute to volume regulation in canine chondrocytes. Br. J. Pharmacol. 168, 1584-1596. doi: 10.1111/j.14765381.2012.02185.x

Lippiat, J. D., Standen, N. B., Harrow, I. D., Phillips, S. C., and Davies, N. W. (2003). Properties of $\mathrm{BK}(\mathrm{Ca})$ channels formed by bicistronic expression of hSloalpha and beta1-4 subunits in HEK293 cells. J Membr. Biol. 192, 141-148. doi: 10.1007/s00232-002-1070-0

Martel-Pelletier, J., Alaaeddine, N., and Pelletier, J. P. (1999). Cytokines and their role in the pathophysiology of osteoarthritis. Front. Biosci. 4:D694-D703.

Mathiessen, A., and Conaghan, P. G. (2017). Synovitis in osteoarthritis: current understanding with therapeutic implications. Arthritis Res. Ther. 19:18. doi: 10.1186/s13075-017-1229-9

McManus, O. B., Helms, L. M., Pallanck, L., Ganetzky, B., Swanson, R., and Leonard, R. J. (1995). Functional role of the beta subunit of high conductance calcium-activated potassium channels. Neuron 14, 645-650. doi: 10.1016/08966273(95)90321-6

Mobasheri, A., Gent, T. C., Womack, M. D., Carter, S. D., Clegg, P. D., and BarrettJolley, R. (2005). Quantitative analysis of voltage-gated potassium currents from primary equine (Equus caballus) and elephant (Loxodonta africana) articular chondrocytes. Am. J. Physiol. Regul. Integr. Comp. Physiol. 289, R172-R180. doi: 10.1152/ajpregu.00710.2004 
Mobasheri, A., Lewis, R., Ferreira-Mendes, A., Rufino, A., Dart, C., and BarrettJolley, R. (2012). Potassium channels in articular chondrocytes. Channels 6, 416-425. doi: 10.4161/chan.22340

Mortaz, E., Adcock, I. M., Shafei, H., Masjedi, M. R., and Folkerts, G. (2012). Role of P2X7 receptors in release of IL-1 $\beta$ : a possible mediator of pulmonary inflammation. Tanaffos 11, 6-11.

Nilius, B., and Droogmans, G. (2001). Ion channels and their functional role in vascular endothelium. Physiol. Rev. 81, 1415-1459. doi: 10.1152/physrev.2001. 81.4 .1415

Noss, E. H., and Brenner, M. B. (2008). The role and therapeutic implications of fibroblast-like synoviocytes in inflammation and cartilage erosion in rheumatoid arthritis. Immunol. Rev. 223, 252-270. doi: 10.1111/j.1600-065X. 2008.00648.x

Orio, P., and Latorre, R. (2005). Differential effects of beta 1 and beta 2 subunits on BK channel activity. J. Gen. Physiol. 125, 395-411. doi: 10.1085/jgp.20040 9236

Petho, Z., Tanner, M. R., Tajhya, R. B., Huq, R., Laragione, T., Panyi, G., et al. (2016). Different expression of beta subunits of the KCa1.1 channel by invasive and non-invasive human fibroblast-like synoviocytes. Arthritis Res. Ther. 18, 103. doi: 10.1186/s13075-016-1003-4

Pretzel, D., Pohlers, D., Weinert, S., and Kinne, R. W. (2009). In vitro model for the analysis of synovial fibroblast-mediated degradation of intact cartilage. Arthritis Res. Ther. 11:R25. doi: 10.1186/ar2618

Roemer, F. W., Felson, D. T., Yang, T., Niu, J., Crema, M. D., Englund, M., et al. (2013). The association between meniscal damage of the posterior horns and localized posterior synovitis detected on T1-weighted contrast-enhanced MRI-The MOST study. Semin. Arthritis Rheum 42, 573-581. doi: 10.1016/j. semarthrit.2012.10.005

Scudieri, P., Caci, E., Venturini, A., Sondo, E., Pianigiani, G., Marchetti, C., et al. (2015). Ion channel and lipid scramblase activity associated with expression of TMEM16F/ANO6 isoforms. J. Physiol. Lon. 593, 3829-3848. doi: 10.1113/ Jp270691

Sellam, J., and Berenbaum, F. (2010). The role of synovitis in pathophysiology and clinical symptoms of osteoarthritis. Nat. Rev. Rheumatol. 6, 625-635. doi: 10.1038/nrrheum.2010.159

Soom, M., Gessner, G., Heuer, H., Hoshi, T., and Heinemann, S. H. (2008). A mutually exclusive alternative exon of slol codes for a neuronal BK channel with altered function. Channels 2, 278-282. doi: 10.4161/chan.2.4.6571

Stevens, A. L., Wishnok, J. S., Chai, D. H., Grodzinsky, A. J., and Tannenbaum, S. R. (2008). A sodium dodecyl sulfate-polyacrylamide gel electrophoresis-liquid chromatography tandem mass spectrometry analysis of bovine cartilage tissue response to mechanical compression injury and the inflammatory cytokines tumor necrosis factor alpha and interleukin-1beta. Arthritis Rheum 58, 489-500. doi: 10.1002/art.23120

Stevens, A. L., Wishnok, J. S., White, F. M., Grodzinsky, A. J., and Tannenbaum, S. R. (2009). Mechanical injury and cytokines cause loss of cartilage integrity and upregulate proteins associated with catabolism, immunity, inflammation, and repair. Mol. Cell Proteomics 8, 1475-1489. doi: 10.1074/mcp.M800181MCP200

Sutton, S., Clutterbuck, A., Harris, P., Gent, T., Freeman, S., Foster, N., et al. (2009). The contribution of the synovium, synovial derived inflammatory cytokines and neuropeptides to the pathogenesis of osteoarthritis. Vet. J. 179, 10-24. doi: $10.1016 / j . t v j 1.2007 .08 .013$

Tanner, M. R., Hu, X., Huq, R., Tajhya, R. B., Sun, L., Khan, F. S., et al. (2015). KCa1.1 Inhibition Attenuates Fibroblast-like Synoviocyte Invasiveness and Ameliorates Disease in Rat Models of Rheumatoid Arthritis. Arthritis Rheumatol 67, 96-106. doi: 10.1002/art.38883
Tanner, M. R., Pennington, M. W., Chauhan, S. S., Laragione, T., Gulko, P. S., and Beeton, C. (2019). KCa1.1 and Kv1.3 channels regulate the interactions between fibroblast-like synoviocytes and T lymphocytes during rheumatoid arthritis. Arthritis Res. Ther. 21:6. doi: 10.1186/s13075-018-1783-9

Uebele, V. N., Lagrutta, A., Wade, T., Figueroa, D. J., Liu, Y., McKenna, E., et al. (2000). Cloning and functional expression of two families of beta-subunits of the large conductance calcium-activated K+ channel. J. Biol. Chem. 275, 23211-23218. doi: 10.1074/jbc.M910187199

van Maanen, M. A., Stoof, S. P., van der Zanden, E. P., de Jonge, W. J., Janssen, R. A., Fischer, D. F., et al. (2009). The alpha7 nicotinic acetylcholine receptor on fibroblast-like synoviocytes and in synovial tissue from rheumatoid arthritis patients: a possible role for a key neurotransmitter in synovial inflammation. Arthritis Rheum 60, 1272-1281. doi: 10.1002/art.24470

Varani, K., De Mattei, M., Vincenzi, F., Tosi, A., Gessi, S., Merighi, S., et al. (2008). Pharmacological characterization of $\mathrm{P} 2 \mathrm{X} 1$ and $\mathrm{P} 2 \mathrm{X} 3$ purinergic receptors in bovine chondrocytes. Osteoarthr. Cartil. 16, 1421-1429. doi: 10.1016/j.joca. 2008.03.016

Waldburger, J. M., Boyle, D. L., Pavlov, V. A., Tracey, K. J., and Firestein, G. S. (2008). Acetylcholine regulation of synoviocyte cytokine expression by the alpha7 nicotinic receptor. Arthritis Rheum 58, 3439-3449. doi: 10.1002/art. 23987

Wang, B., and Brenner, R. (2006). An S6 mutation in BK channels reveals beta1 subunit effects on intrinsic and voltage-dependent gating. J. Gen. Physiol. 128, 731-744. doi: 10.1085/jgp.200609596

Williams, A. (2014). Proteomic Studies of an Explant Model of Equine Articular Cartilage in Response to Proinflammatory and Anti-Inflammatory Stimuli. $\mathrm{PhD}$ Thesis, University of Nottingham, Nottingham.

Williams, A., Smith, J. R., Allaway, D., Harris, P., Liddell, S., and Mobasheri, A. (2011). Strategies for optimising proteomic studies of the cartilage secretome: establishing the time course for protein release and evaluating responses of explant cultures to il-1 beta, tnf-alpha and carprofen. Osteoarthr.Cartil. 19, S209-S209.

Yang, C. T., Zeng, X. H., Xia, X. M., and Lingle, C. J. (2009). Interactions between beta subunits of the KCNMB family and Slo3: beta4 selectively modulates Slo3 expression and function. PLoS One 4:e6135. doi: 10.1371/journal.pone.000 6135

Yoo, S. A., Park, B. H., Park, G. S., Koh, H. S., Lee, M. S., Ryu, S. H., et al. (2006). Calcineurin is expressed and plays a critical role in inflammatory arthritis. J. Immunol. 177, 2681-2690. doi: 10.4049/jimmunol.177.4.2681

Zerbino, D. R., Achuthan, P., Akanni, W., Amode, M. R., Barrell, D., and Bhai, J. (2018). Ensembl 2018. Nucleic Acids Res. 46, D754-D761. doi: 10.1093/nar/ gkx1098

Zhou, Y., and Lingle, C. J. (2014). Paxilline inhibits BK channels by an almost exclusively closed-channel block mechanism. J. Gen. Physiol. 144, 415-440. doi: 10.1085/jgp.201411259

Conflict of Interest: The authors declare that the research was conducted in the absence of any commercial or financial relationships that could be construed as a potential conflict of interest.

Copyright (c) 2020 Haidar, O’Neill, Staunton, Bavan, O’Brien, Zouggari, Sharif, Mobasheri, Kumagai and Barrett-Jolley. This is an open-access article distributed under the terms of the Creative Commons Attribution License (CC BY). The use, distribution or reproduction in other forums is permitted, provided the original author(s) and the copyright owner(s) are credited and that the original publication in this journal is cited, in accordance with accepted academic practice. No use, distribution or reproduction is permitted which does not comply with these terms. 